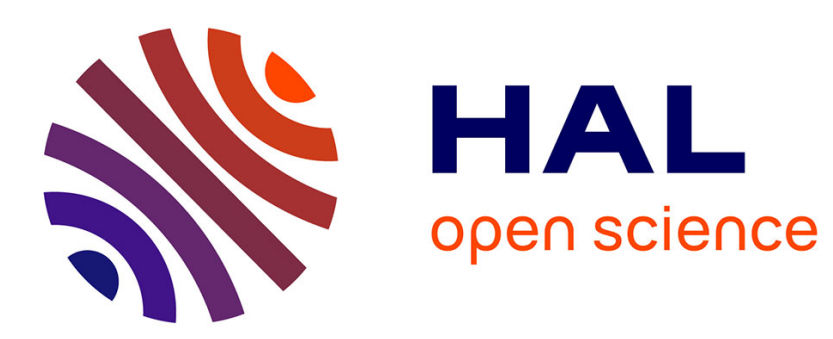

\title{
Assessing the emergence of pro-biodiversity practices in citizen scientists of a backyard butterfly survey
}

Nicolas Deguines, Karine Princé, Anne-Caroline Prévot, Benoît Fontaine

\section{To cite this version:}

Nicolas Deguines, Karine Princé, Anne-Caroline Prévot, Benoît Fontaine. Assessing the emergence of pro-biodiversity practices in citizen scientists of a backyard butterfly survey. Science of the Total Environment, 2020, 716, pp.136842. 10.1016/j.scitotenv.2020.136842 . hal-02553145

\section{HAL Id: hal-02553145 \\ https://hal.science/hal-02553145}

Submitted on $10 \mathrm{Jul} 2020$

HAL is a multi-disciplinary open access archive for the deposit and dissemination of scientific research documents, whether they are published or not. The documents may come from teaching and research institutions in France or abroad, or from public or private research centers.
L'archive ouverte pluridisciplinaire HAL, est destinée au dépôt et à la diffusion de documents scientifiques de niveau recherche, publiés ou non, émanant des établissements d'enseignement et de recherche français ou étrangers, des laboratoires publics ou privés. 
the Total Environment

Elsevier Editorial system(tm) for science of

Manuscript Draft

Manuscript Number: STOTEN-D-19-15895R1

Title: Assessing the emergence of pro-biodiversity practices in citizen scientists of a backyard butterfly survey

Article Type: Research Paper

Keywords: Citizen scientists, Lepidoptera, Pro-environmental behaviors, Nature-based monitoring program, Urban green spaces.

Corresponding Author: Dr. Nicolas Deguines, Ph.D.

Corresponding Author's Institution: Université Paris-Sud

First Author: Nicolas Deguines, Ph.D.

Order of Authors: Nicolas Deguines, Ph.D.; Karine Princé; Anne-Caroline Prévot; Benoît Fontaine

Abstract: By monitoring biodiversity through citizen science programs, volunteers help scientists gather data at unprecedented temporal and geographical scales, and increase their knowledge and awareness of the surrounding biodiversity. While scientific outcomes of such programs may in the long run improve the state of biodiversity by informing environmental policies, direct benefits to biodiversity could arise locally if such experience of nature lead to biodiversity-friendly behaviors in volunteers. However, whether engagement into nature-based CS programs promotes individual behavioral changes remains poorly known. Here, we explored whether sustained participation in a nature-based citizen science program, called the French Butterfly citizen science project, is associated with changes in individual gardening practices. Specifically, using information provided by volunteers ( $\mathrm{n}=2362$, from 2006 to 2013), we quantified gardening practices that directly affect butterflies, through two different indices: provision of nectar resources, and pesticide use.

We found quantitative evidence that individual gardening practices shifted with multi-year participation, towards increased provision of nectar resources and decreased use of pesticides. However, the reduction in pesticide use was weakened if the backyard was used to grow fruits or vegetables. Other variables such as the size of the backyard affected gardening practices.

This study reveals that participation in a nature-based citizen science program can prompt biodiversity-friendly behaviors, and highlights citizen science not only as a way to collect ecologically sound data but also as a direct conservation tool. Yet, future interdisciplinary research remains critical to overcome factors limiting firm adoption of pro-biodiversity behaviors.

Response to Reviewers: Ms. Ref. No.: STOTEN-D-19-15895

Title: Assessing the emergence of pro-biodiversity practices in citizen scientists of a backyard butterfly survey Journal: Science of the Total Environment 


\section{Garden Butterfly Observatory}

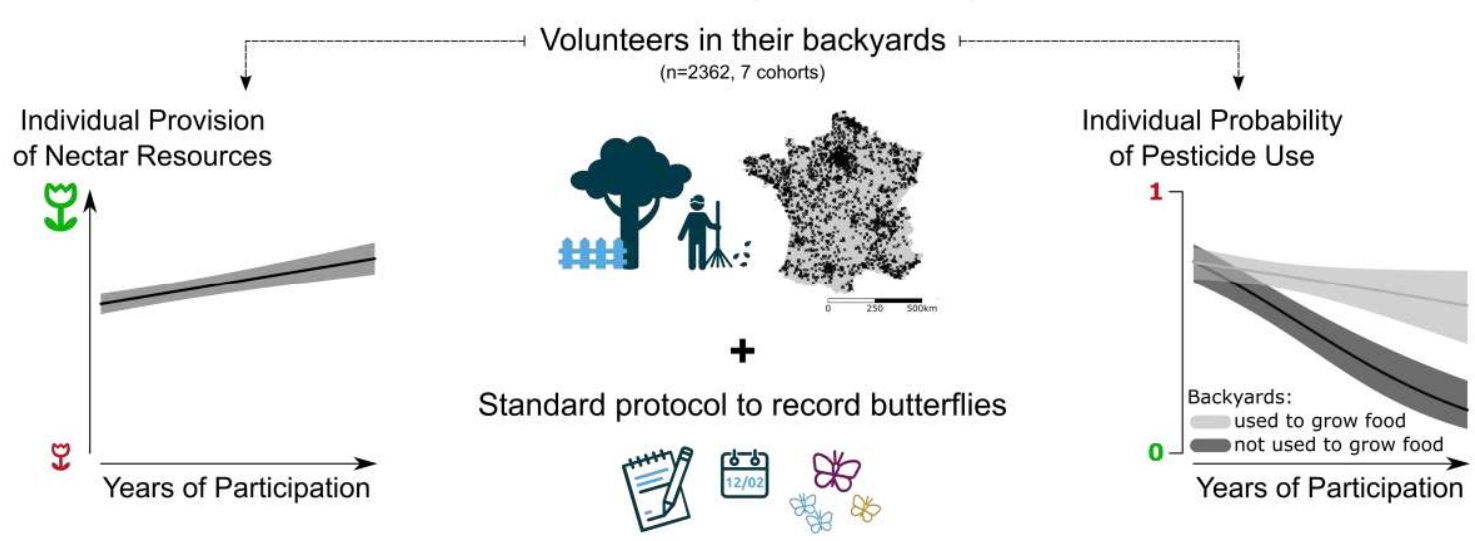




\section{HIGHLIGHTS}

2 - Annual information on gardening practices (2006-2013, 2362 volunteers) are analyzed

3 - Gardening practices that benefit butterflies increase with sustained participation

$4 \quad$ - Reduction in pesticide use was greatest in backyards not used to grow food

5 - Changing participant behaviors, citizen science can have direct conservation benefits 


\section{ABSTRACT}

By monitoring biodiversity through citizen science programs, volunteers help scientists gather data at unprecedented temporal and geographical scales, and increase their knowledge and awareness of the surrounding biodiversity. While scientific outcomes of such programs may in the long run improve the state of biodiversity by informing environmental policies, direct benefits to biodiversity could arise locally if such experience of nature lead to biodiversity-friendly behaviors in volunteers. However, whether engagement into naturebased CS programs promotes individual behavioral changes remains poorly known.

Here, we explored whether sustained participation in a nature-based citizen science program, called the French Butterfly citizen science project, is associated with changes in individual gardening practices. Specifically, using information provided by volunteers $(\mathrm{n}=$ 2362, from 2006 to 2013), we quantified gardening practices that directly affect butterflies, through two different indices: provision of nectar resources, and pesticide use.

We found quantitative evidence that individual gardening practices shifted with multiyear participation, towards increased provision of nectar resources and decreased use of pesticides. However, the reduction in pesticide use was weakened if the backyard was used to grow fruits or vegetables. Other variables such as the size of the backyard affected gardening practices.

This study reveals that participation in a nature-based citizen science program can prompt biodiversity-friendly behaviors, and highlights citizen science not only as a way to collect ecologically sound data but also as a direct conservation tool. Yet, future interdisciplinary research remains critical to overcome factors limiting firm adoption of probiodiversity behaviors. 
KEYWORDS: Citizen scientists; Lepidoptera; Pro-environmental behaviors; Nature-based monitoring program; Urban green spaces.

\section{INTRODUCTION}

Thirty years after Diamond's description of the Evil Quartet causing extinctions (Diamond, 1989), habitat change remains among the most important threats to biodiversity worldwide (Godet and Devictor, 2018; IPBES, 2019). In Europe, urbanization is the prime driver of land use change (EEA, 2010). The suite of environmental degradation associated with urbanization (e.g., increase in impervious surfaces, air and soil pollution) generally leads to a reduction in the diversity of a wide range of taxa (Marzluff, 2001; McKinney, 2006) and a biotic homogenization at large geographical scales (Deguines et al., 2016; La Sorte et al., 2007; McKinney, 2006). Improving the suitability of urban environments for wild species thus is a conservation issue (Hall et al., 2017).

Within cities, backyards may constitute $16-47 \%$ of urban green space in Europe (based on estimates from the UK and France), and as much as $86 \%$ as found in León, Nicaragua (Baldock et al. 2019; Goddard et al., 2010; Mimet et al., 2020). Urban backyards can act as refuges for biodiversity (Goddard et al., 2010; Levé et al., 2018; Sperling and Lortie, 2010), and as corridors connecting green spaces (Mimet et al., 2020; Rudd et al., 2002). Yet, to fulfil this potential, there is a need to improve backyard suitability for biodiversity (Daniels and Kirkpatrick, 2006; Fontaine et al., 2016; Pardee and Philpott, 2014).

Citizen science (CS), defined as a "method of integrating public outreach and scientific data collection" (Cooper et al., 2007) through "the involvement of volunteers in research" (Dickinson et al., 2010), could help change the management of these private spaces for greater biodiversity benefits. The success of nature-based CS programs in advancing the 
field of ecology is well established (McKinley et al., 2017). From a conservation perspective, Couvet and colleagues (2008) highlighted the greater social legitimacy of CS biodiversity indicators, generated from public-collected data, which may help bridge the gap between research findings and policy implementation (Arlettaz et al., 2010; Toomey et al., 2017). Participating in CS programs may also increase the biodiversity knowledge of volunteers (Deguines et al., 2018; Silvertown et al., 2015), and these programs are further hoped to commit volunteers into heightened pro-environmental behaviors (Chase and Levine, 2018; Toomey and Domroese, 2013). To date, however, evidence on whether pro-environmental behaviors are adopted by volunteers is scarce and based on qualitative information from a limited number of volunteers and/or a short period of time (Cosquer et al., 2012; Crall et al., 2013; Jordan et al., 2011; Lewandowski and Oberhauser, 2017; Sharma et al., 2019). A temporal and quantitative assessment is lacking to assess this issue. In this study, we investigated whether backyard owners joining the French Butterfly citizen science project (BCSP) adopt pro-environmental behaviors in their backyards.

Butterflies forage on nectar from flowers and the amount of nectar resources is a strong driver of butterfly abundance and richness in anthropogenic landscapes (Luppi et al., 2018).

Conversely, butterflies are negatively affected by pesticides (Forister et al., 2016; Gilburn et al., 2015). Provisioning nectariferous plants and reducing the use of pesticides are two conservation actions with demonstrated benefits for butterflies in backyards (Fontaine et al., 2016). Based on data from 2362 BCSP volunteers who participated two to eight years between 2006 and 2013, we assessed how participation may foster pro-environmental behaviors. We focused on two behaviors that have a direct impact on butterflies and biodiversity, i.e., the provision of nectar resources and the use of pesticides in backyards. Research in environmental psychology showed that the simple provision of information is not enough, on its own, to induce behavioral changes (Byerly et al., 2018; 
Osbaldiston and Schott, 2012; Schultz, 2011). However, more than simply receiving general information about surrounding biodiversity and how to support it, volunteers in CS programs live so-called "experiences of nature" (Clayton et al., 2017), with explicit attention to biodiversity, that could facilitate pro-biodiversity practices (Prévot et al., 2018). We therefore expected that participation would encourage volunteers to shift towards butterfly-friendly gardening practices. Specifically, we hypothesized that sustained participation for multiple years can lead to adopting the two studied pro-biodiversity practices (i.e., provisioning more nectar resources and decreasing pesticide use). Additionally, within-year degree of participation during the period of sustained engagement (Ponciano and Brasileiro, 2014) may be seen as a quantitative measure of motivation for monitoring butterflies and we expected it to be associated with higher provision of nectar resources and lower use of pesticides.

However, individual behavioral changes are constrained by a set of interacting factors, such as attitudes, habits, personal capabilities, social norms, and context (Stern, 2000). In particular, backyard's management reflects the identity of its owners (e.g., interests and activities such as recreation, eating, growing fruits or vegetables, connecting to nature; Clayton, 2007). There is also evidence that personal experience and social norms can influence practices (Ajzen, 1991; Goddard et al., 2013; Uren et al., 2015). For example, gardeners from rural origins or inhabiting rural areas may use more pesticides in their backyards compared with urban counterparts (Barrault, 2012; Coppin et al., 2002). Finally, backyard management is also influenced by its size (Barrault, 2012; Clayton, 2007; Freeman et al., 2012; Riboulot-Chetrit et al., 2018). Owners of large garden with a vegetable garden and fruit trees may be particularly prone to using pesticides (Barrault, 2012). In our analyses, we thus accounted for the role of backyard size and its position along an urbanization gradient, as well as the presence of a vegetable garden or fruit trees in the backyard in determining pro-biodiversity practices of volunteers. Specifically, we tested whether the latter 
four variables could mediate the effect of sustained participation on the provisioning of nectar resources or the use of pesticides by volunteers in their backyard.

Lastly, general attention towards environmental and biodiversity issues have gained momentum in European countries (European Commission, 2013). These variations in collective norms could be linked with potential changes in gardening practices. In this regard, our study assesses across seven cohorts of volunteers (i.e., joining the BCSP program in seven consecutive years) whether behavioral changes are associated to being involved in this naturefocused CS program, strengthening our confidence that any observed pattern may not be confounded with temporal changes occurring in the overall French population.

\section{MATERIALS and METHODS}

\section{$\underline{2.1 \text { Data collection and localization }}$}

The Opération Papillons - Vigie-Nature (hereafter "BCSP": Butterfly citizen science project database for France; Noé - Muséum national d'Histoire naturelle, Paris, France; https://www.sciences-participatives-au-jardin.org/) is a citizen science program in which volunteers record butterflies in their backyard following a simple protocol (Fontaine et al., 2016). Upon registration, volunteers give their consent that the data they provide can be used for scientific studies. The program is open to the general public with no entomological skills required, as butterfly identification is based on a closed list of 28 species/group of species. Each year from March to October, volunteers identify and count butterflies in their backyard and are invited to upload monthly lists of butterfly species abundance. Within a month, no minimum amount of time of observations is required (but participants qualitatively report their frequency of observations). In average, volunteers participated (i.e., uploaded butterfly counts) 4.98 months annually $(\mathrm{SE}=0.04$ months, $\min .=1, \max .=8)$. To motivate 
volunteers, a monthly newsletter reported on overall participation, highlighted a 'Butterfly of the month', and shared results of the project; additionally, a 'tip of the month' and a 'plant of the month' sections could suggest pro-environmental behaviors (e.g., traditional crop varieties may better tolerate pests and reduce the need for pesticides).

We used data from the first eight years of the program (2006-2013). We reduced our dataset to volunteers who uploaded butterfly counts (i.e., participated) for several consecutive years, the minimum being two years (regardless the number of months of participation per year). Some volunteers interrupted their participation for one or several years. Because we wanted to assess potential effects of sustained (i.e., continuous) involvement into the BCSP program, we further restrained our dataset to volunteers with no annual break in participation. Upon registration, participants provided the size of their backyard as well as its localization (the municipality - smallest administrative district in France). Backyard size ranged from $20 \mathrm{~m}^{2}$ to $6000 \mathrm{~m}^{2}\left(\right.$ median $\left.=1000 \mathrm{~m}^{2}, \mathrm{Q} 1=600 \mathrm{~m}^{2}, \mathrm{Q} 3=2000 \mathrm{~m}^{2}\right) . \mathrm{We}$ characterized urbanization context of each backyard by computing the percentage of urban land use in the municipality (using "Artificial surfaces" from the first level of the Corine Land Cover 2006 database; Bossard et al., 2006); it ranged from $0 \%$ to $100 \%$ (median $=7 \%$, Q1 = $2 \%, \mathrm{Q} 3=26 \%$ ). While backyard size and urbanization context were slightly correlated (Kendall's rank correlation $\operatorname{tau}=-0.33, P<0.001$ ), there was no worrisome collinearity that would prevent their inclusion in the same statistical model (see 2.3 and computations of variance inflation factors). Participants also declared the presence of a vegetable garden or of fruit trees.

\section{$\underline{2.2 \text { Volunteers' pro-biodiversity gardening practices }}$}

Participants were annually asked to fill out a questionnaire regarding the presence of some specific backyard features and plants, from a closed list, as well as their use of 
pesticides. None of the backyard features, plants, or level of pesticide use was a requirement to participate. Based on this information, we computed the two following indices: nectar resources, and pesticide use.

We used Bergerot and colleagues' (2010) ranking of plant attractiveness for butterflies (related to nectar production) to compute the index of nectar resources in the backyard as following: the presence of butterfly bushes (Buddleja spp.), knapweeds (Centaurea spp.), lavenders (Lavandula spp.) or brambles (Rubus spp.) was scored 3 for each taxon; the presence of valerians (Valeriana spp.), clovers (Trifolium spp.) or aromatic plants (e.g., Rosmarinus officinalis/spp., Thymus spp.) was scored 2 for each; the presence of geraniums (Pelargonium spp.) was scored 1. The final index was computed by summing all these scores (range: 0-19). All plants are common backyard species across the bioclimatic regions of France.

The questions regarding pesticide use in the backyard varied in the period of the study. From 2006 to 2009, we asked 'Is your garden treated with pesticides (e.g., insecticides, antkillers, aphid-killers or fungicides)?' and volunteers could answer 'Never', 'Occasionally', or 'Regularly'. After 2009, this question was split into 5 more-detailed questions: 1) 'Are you using insecticides?', 2) '[...] herbicides?', 3) '[...] fungicides?', 4) '[...] slug pellets?', and 5) '[...] Bordeaux mixture?' (the latter is a fungicide authorized in organic agriculture); again, volunteers could answer 'Never', 'Occasionally', or 'Regularly' to each of these questions. Because the answer 'Regularly' was rarely ticked (2.17\%), we converted responses as binary variables (0 - 'Never', 1 - 'Occasionally' or 'Regularly'). To obtain for the whole 2006-2013 period a consistent index of pesticide use within backyards, we lumped responses to the 5 questions asked after 2009 into a single one: 0 - 'Never' answered to each question, 1 'Occasionally' or 'Regularly' answered to at least one question. 
Some volunteers did not fill this questionnaire every year, in which case one or both

indices could not be computed for a given year. We therefore further restricted our dataset to volunteers that provided backyard information for at least two years, including the first year of their participation to serve as a baseline against which changes in garden practices following sustained participation could be assessed. Our final dataset included 2362 volunteers distributed across all mainland France (Fig. 1).

\section{$\underline{2.3 \text { Statistical analyses }}$}

As there were multiple observations per volunteer, we relied on mixed-effects modeling to assess whether volunteers' individual gardening practices (provision of nectar resources and pesticide use) changed over time since the start of participation. All statistical analyses were performed with R version 3.5.2 (R Core Team, 2018) and, in particular, R package lme4 (Bates et al., 2015). Volunteers were structured in seven cohorts corresponding to their first year of participation (Fig. 1): $2006(n=767), 2007(n=722), 2008(n=355)$, $2009(n=97), 2010(n=130), 2011(n=144)$, or $2012(n=147)$.

The index of nectar resources displayed an approximately Gaussian distribution; thus, although it could only take integer values between 0 and 19 , we decided to include it as the response variable of a linear-mixed effect model. Explanatory variables included the time (in years) since a volunteer started participating (sustained participation), the mean number of months of participation per year for each volunteer (within-year participation), the size of the backyard (backyard size; log transformed to improve residuals behavior), the percentage of urban land use in the volunteer's municipality (urbanization context), the presence of a vegetable garden in the backyard (vegetable garden), and the presence of fruit trees in the backyard (fruit trees). We further tested whether these four latter variables mediated the effect of sustained participation on the index of nectar resources by including each in a two-way 
interaction with 'sustained participation' in the model. We included the longitude and latitude of volunteers' municipality (its centroid) to account for potential spatial auto-correlation in our dataset. There were multiple observations per volunteer (from two to eight), and volunteers were clustered in seven cohorts (Fig. 1). We accounted for these dependences in our dataset by including volunteers' identification code, nested within cohorts, as a random effect. Intercept and slope of 'sustained participation' was allowed to vary among volunteers within cohorts [coded as $(1+$ sustained participation $\mid$ cohort_ID : volunteer_ID $)]$. Additionally, to account for potential annual unmeasured variations (e.g., climate effects on plant growth, newsletters' content sent to volunteers, media coverage of biodiversity issues), we also included year as a random effect on the intercept. We computed variance inflation factors (Zuur et al., 2009) of all explanatory variables and found no evidence of collinearity (all VIF values $<1.5$ ). Assumptions of homoscedasticity and normality of residuals of the model were met. Spatial independence of model residuals was confirmed graphically by computing a variogram (Zuur et al., 2009). Two-way interactions which had no significant effects $(P>0.05)$ were removed from the models to better interpret single effects. This mixed-effect model was based on a sample size of 9009 observations from 2362 volunteers. To investigate variations of pesticide use by volunteers in their backyard, we performed a generalized linear mixed-effects model with a binomial family and a logit link. The response variable was binary, corresponding to using pesticides (1) or not (0). We accounted for the change in how information regarding pesticide use within backyards was gathered and treated (see above Volunteers' pro-biodiversity gardening practices) by including the type of recorded information regarding pesticide use as a fixed effect (two levels: single question and five questions). Other fixed effects were the same as in the linear mixed-effects model presented above. Specifying the same random-effect structure as above led to a singular model fit. To resolve this issue, we followed Bates and colleagues (2018) and 
simplified the random effect structure by removing the effect of year on the intercept. There was no collinearity among our explanatory variables (VIF values $<1.5$ ) and spatial independence of model residuals was confirmed with a variogram. Two-way interactions which had no significant effects $(P>0.05)$ were removed from the model to better interpret single effects. This mixed-effect model was based on a sample size of 8636 observations from 2362 volunteers; observations number differs from the nectar resources linear mixed-effects model because volunteers were allowed to only partially fill in the backyard information annual questionnaire. We carried out post-hoc analyses to further interpret how significant effects of two interactions ('sustained participation $x$ vegetable garden' and 'sustained participation $x$ fruit trees') affected pesticide use. Specifically, we ran separate generalized linear mixed-effects models for volunteers with or without a vegetable garden (regardless the presence of fruit trees) and with or without fruit trees (regardless the presence of a vegetable garden).

Duration of sustained participation ranged from two to eight years and was unbalanced (765 and 166 volunteers participated during two and eight years respectively; the median sustained participation duration was three years). To ensure this would not lead to biased estimates of the relationships between explanatory variables and gardening practices, we performed a randomization procedure (Manly, 2006). First, we randomly sampled (with replacement) 166 volunteers from each participation duration to generate a random dataset. Second, we ran the mixed-effects models to this randomly sampled dataset, and repeated this procedure over 1000 iterations. We then compared the observed estimates (from the observed whole dataset) with the distribution expected with constant number of participants (166) per sustained participation duration (obtained from the 1000 iterations). We concluded from this procedure that results obtained from models using the observed (i.e., whole) dataset can be trusted (Supporting Information). 


\section{RESULTS}

Both indices of gardening practices significantly changed with sustained participation (i.e., the time in years since entering the Butterfly citizen science project), and a set of other explanatory variables had effects on their own or mediated participation effects (Table 1).

\section{$\underline{3.1 \text { Nectar resources in backyards }}$}

The index of nectar resources significantly increased with sustained participation

(Fig. 2a), and we found no evidence that this effect was mediated by other backyard variables (size, urbanization context, presence of a vegetable garden or fruit trees; Table 1). In average, after eight years of participation, the index of nectar resources increased by $13.7 \%$. Withinyear participation was also significantly positively associated with backyard nectar resources resources increased by $1 \%$. Backyard size was strongly and positively correlated with nectar resources (Fig. 2c), with the index of nectar resources increasing by $33 \%$ from $100 \mathrm{~m}^{2}$ to $1000 \mathrm{~m}^{2}$ and then heading toward a plateau. Increasing urbanization context was significantly correlated with lower nectar resources in backyards (Fig. 2d). Finally, backyards that included a vegetable garden or fruit trees were associated to higher provisioning of nectar resources (Fig. 2e-f).

\section{$\underline{3.2 \text { Pesticide use in backyards }}$}

The use of pesticides in backyards was significantly correlated with sustained participation; however, this relationship depended on whether or not volunteers had a vegetable garden or fruit trees in their backyard (Table 1). 

not have a vegetable garden in their backyard, but this relationship was weaker for volunteers

277

278 tending a vegetable garden (Fig. 3a). Yet, post-hoc analyses detected significant effects of sustained participation on pesticide use in volunteers without or with a vegetable garden ( $P=0.005$ and $P<0.001$ based on a sample size of 3052 and 5584 observations respectively). After eight years of participation, the probability of pesticide use decreased by $78 \%$ and $23 \%$ in volunteers without or with a vegetable garden respectively. Similarly, sustained participation was associated with lower pesticide use by volunteers who did not have fruit trees in their backyard, but this relationship was weaker in volunteers having fruit trees (Fig. 3b). Post-hoc analyses revealed a significant relationship between sustained participation and pesticide use by volunteers having fruit trees in their backyard or not $(P<0.001$ and $P=0.010$ based on a sample size of 6824 and 1812 observations respectively). After eight years of participation, the probability of pesticide use in volunteers without or with a vegetable garden decreased by $73 \%$ and $37 \%$ respectively. Additionally, backyard size was associated to increased probability of using pesticides (Fig. 3c). From a $100 \mathrm{~m}^{2}$ to a $1000 \mathrm{~m}^{2}$ backyard, probability of using pesticides increased by $28 \%$.

\section{DISCUSSION}

Using temporal data on gardening practices from a nature-based citizen science program, we provided strong evidence that shifts towards biodiversity-friendly gardening practices may occur through CS volunteering. To our knowledge, this is the first time that an assessment of whether participating in a nature-based CS programs is associated to the 
implementation of pro-biodiversity actions is based on such a large number of volunteers, surveyed annually over multiple years.

We found positive correlations between sustained participation and level of probiodiversity practices, i.e. growing nectar-rich flowering plants and decreasing pesticide use. This is consistent with previous results from Cosquer and colleagues (2012), who carried out interviews of 30 volunteers from the same CS program. Similarly, a recent study reported that 95\% of 139 volunteers from different butterfly CS programs across the United States declared participating more in conservation actions since engaging in one of their program (Lewandowski and Oberhauser, 2017). However, as these authors noted, volunteers could have increased their involvement regardless of joining a CS program, following potential changes in social norms regarding environmental and biodiversity issues. In this regard, an additional strength of the evidence presented here relies in our dataset including seven cohorts of volunteers joining the BCSP program in consecutive years (Fig. 1), and observed changes in gardening practices can be attributed with greater confidence to joining this nature-based CS program. Our quantitative and large-scale approach thus complements the existing body of qualitative evidence (Cosquer et al., 2012; Lewandowski and Oberhauser, 2017), and allows emphasizing that, beyond the acknowledged value for research in ecology, nature-based CS can also directly enhance local conservation measures at potentially broad geographical scale.

Our analyses also highlighted the importance of other variables than participation in affecting levels of pro-biodiversity practices. In particular, backyard size was the strongest predictor of nectar resources provisioning and a substantial one of pesticide use. Interestingly, backyard size had contrasting effects as larger backyards had higher nectar resources (i.e., a pro-biodiversity practice), but owners used more pesticides (i.e., a detrimental practice for biodiversity). Among the eight groups of plants used to calculate the nectar index, only two are spontaneous, while the presence of the others depends on the gardener decision to plant 
them. Such decision is most likely influenced by the physical constraints imposed by the size of the backyard, limiting the space that can be dedicated to different activities. The reasons for owners of larger backyards to harbor greater nectar resources cannot be determined from our dataset, and the aesthetic value of flowers may be the prime motivation, more than promoting biodiversity (Clayton, 2007). In line with this, greater pesticide use in large backyards appeared to be mostly due to greater application of herbicides and Bordeaux mixture (20102013 data from detailed pesticide use by volunteers), suggesting the will to maintain safety and order by controlling unwanted vegetation (Clayton, 2007; Riboulot-Chetrit et al., 2018). Whether a backyard was used to grow food had multiple effects on pro-biodiversity practices implemented by volunteers. Greater amount of nectar resources was found in backyards where a vegetable garden or fruit trees were present. This could be interpreted as a way for gardeners to attract pollinators required for crop pollination [see for example (Torres et al., 2017) in the context of community gardening], but it could simply be that gardeners tending a vegetable garden or fruits trees enjoy growing plants and thus are more likely to spend time planting different species; additional data would be needed to investigate this and other motives that volunteers may have in the present case. Most importantly, the presence of a vegetable garden or fruit trees in backyards weakened - but did not prevent - the reduction in pesticide use associated to sustained participation. Greater use of pesticides by backyard owners growing food had been found previously (Barrault, 2012); therefore, the fact that participation to nature-based CS was able to prompt a reduction in using these chemicals in such context is very promising. Indeed, while the ban on the domestic use of some pesticides enforced in France since January 2019 should improve backyard quality for biodiversity, routine-experience of nature as proposed by nature-based CS programs may help prevent shifts towards pesticides considered as less harmful but that can still have detrimental 
environmental effects (e.g., the Bordeaux mixture, used in organic agriculture and remaining allowed for domestic use; Bourdais, 1999).

Studies based on self-reported data may be prone to the two following limits. First, researchers may obtain more responses from a subset of highly motivated persons. In the present study, we maximized the number of volunteers that we could consider in the analyses, including every volunteer of the BCSP program participating for at least two consecutive years and from whom we had received backyard information in at least the first year of participation and another year. Additionally, we ran a randomization procedure to check that the reduced number of long-term volunteers did not bias results from our mixed-effects modeling (Supporting Information). Second, respondents may be biased in their reporting, being influenced by what is thought of as socially desirable. In our case, the primary use of the backyard data was not to study volunteers' actions or behaviors in their backyard but to understand the influence of gardening practices on butterflies. This clearly advertised biodiversity-focused objective may have prevented biased reporting due to social desirability. Indeed, the reported data were used by Fontaine and colleagues (2016) who successfully detected positive and negative effects of the index of nectar resources and pesticide use on butterflies, respectively, as expected from the literature (Forister et al., 2016; Gilburn et al., 2015; Luppi et al., 2018). Thus, while our dataset may not be exempt of bias, it likely well describes practices in volunteers of the BCSP program.

Our findings confirmed that participation to nature-based CS program can prompt probiodiversity practices in volunteers, with direct local benefits for conservation. An analysis of interviews of 30 volunteers of the BCSP suggested that the development of awareness of butterflies and understanding of their ecological needs led to the intentional implementation of pro-conservation actions (Cosquer et al., 2012). Regular attentive observations of butterflies for the program constituted routine experiences of nature that may have primed 
volunteers towards adopting pro-biodiversity practices (Prévot et al. 2018, 2017). As recommended elsewhere (Lewandowski and Oberhauser, 2017), we encouraged the adoption of biodiversity-friendly gardening practices (through newsletters): this may have been particularly effective in spurring changes in backyard management, because volunteers were environmentally concerned and declared that 'helping biodiversity conservation' was one of their main reasons for participating (Cosquer et al., 2012; Prévot et al., 2017). It is also possible that belonging to a community of observers (e.g., receiving newsletters, engaging in a program led by the National Museum of Natural History and Noé, an environmental NGO) has favored changes in attitudes and social norms towards greater acceptance of backyards features benefitting butterflies. Last but not least, our results may be particularly expected from a citizen science program engaging backyard owners. Indeed, volunteers managed their backyard the way they chose, and perceived control to meet a particular outcome (i.e., perception of self-efficacy) was found to be positively associated with the probability to engage into pro-environmental behaviors (Ajzen, 1991; Hines et al., 1987). Sustained participation to a nature-based CS program may allow experiencing the causality between practices and biodiversity outcomes (Cosquer et al., 2012), and the shift towards probiodiversity behaviors would then be likely, thanks to high perceived control. Complementary data would be required to understand how gardeners' experience, knowledge, resources, or available time may influence behavioral changes in the context of participation in citizen science.

Backyards hold great potential as 'pollinator hotspots' in cities (Baldock et al., 2019; Levé et al., 2018), and are thus of paramount importance for urban conservation strategies of butterflies and the wider flower visitor fauna. Yet, improving their quality through biodiversity-friendly management (e.g., planting nectar-rich or host plants, reducing mowing frequency) will require wishful personal involvement from the owners. We highlighted the 
roles of different factors in determining adoption of pro-biodiversity practices by citizen scientists. This calls for collaborations between biologists and social scientists if we are to succeed in further changing behaviors towards conservation goals (Schultz, 2011). Different tools exist to favour pro-environmental changes, but uncertainties remain regarding their efficiency under various conditions and for different behaviors (Byerly et al., 2018; Schultz, 2014). Beyond provisioning information and encouraging volunteers to engage in conservation, biologists involved in nature-based CS programs should embrace collaborations with psychological scientists to design and test interventions for enhancing adoption of probiodiversity behaviors (Clayton et al., 2013). For example, by designing experimental emails or newsletters, we could test the effectiveness of different strategies - such as Messenger effect, Norms, or Salience (Byerly et al., 2018) - in spurring behavioral changes in volunteers. Given the tens of thousands of citizen scientists monitoring biodiversity in their backyards in Europe and North America (Cannon et al., 2005; Lorrillière et al., 2018; Princé and Zuckerberg, 2015), this exciting avenue of interdisciplinary research represents critical stakes for biodiversity conservation in cities.

\section{SUPPORTING INFORMATION}

Methodological details and results of the randomization procedure are available online (Appendix S1).

\section{ACKNOWLEDGMENTS}

We thank the thousands of volunteers of the Opération Papillons - Vigie Nature (2019) program for their effort and time monitoring butterflies. We are grateful to the NGO Noé and 
to the Vigie-Nature team for managing the citizen science program, to A-C Maurice and members of the CESCO for fruitful methodological discussions, and to two anonymous reviewers for helpful suggestions. ND was funded by the BiodivERsA3-2015-104 (BIOVEINS) grant, and KP was funded by the ANR-17-CE04-0012 (VGI4BIO). Funding sources were not involved in any step of this study.

\section{AUTHORS CONTRIBUTIONS}

Nicolas Deguines: Conceptualization, Methodology, Formal Analysis, Visualization, Writing - Original Draft, Writing - Reviewing and Editing.

Karine Princé: Conceptualization, Methodology, Writing - Reviewing and Editing.

Anne-Caroline Prévot: Conceptualization, Writing - Reviewing and Editing.

Benoît Fontaine: Conceptualization, Data Curation, Methodology, Writing - Reviewing and Editing, Monitoring Scheme Management.

\section{REFERENCES}

Ajzen, I., 1991. The theory of planned behavior. Organ. Behav. Hum. Decis. Process. 50, 179-211. https://doi.org/10.1016/0749-5978(91)90020-T

Arlettaz, R., Schaub, M., Fournier, J., Reichlin, T.S., Sierro, A., Watson, J.E.M., Braunisch, V., 2010. From publications to public actions: when conservation biologists bridge the gap between research and implementation. Bioscience 60, 835-842. https://doi.org/10.1525/bio.2010.60.10.10

Baldock, K.C.R., Goddard, M.A., Hicks, D.M., Kunin, W.E., Mitschunas, N., Morse, H., Osgathorpe, L.M., Potts, S.G., Robertson, K.M., Scott, A. V., Staniczenko, P.P.A., 
Stone, G.N., Vaughan, I.P., Memmott, J., 2019. A systems approach reveals urban pollinator hotspots and conservation opportunities. Nat. Ecol. Evol. 3, 363-373. https://doi.org/10.1038/s41559-018-0769-y

Barrault, J., 2012. Les pratiques de jardinage face aux risques sanitaires et environnementaux des pesticides. Les approches différenciées de la France et du Québec. Université de Toulouse II - Le Mirail.

Bates, D., Kliegl, R., Vasishth, S., Baayen, H., 2018. Parsimonious mixed models. ArXiv eprint.

Bates, D., Mächler, M., Bolker, B.M., Walker, S.C., 2015. Fitting linear mixed-effects models using lme4. J. Stat. Software2 67, 1-48. https://doi.org/10.18637/jss.v067.i01

Bergerot, B., Fontaine, B., Renard, M., Cadi, A., Julliard, R., 2010. Preferences for exotic flowers do not promote urban life in butterflies. Landsc. Urban Plan. 96, 98-107. https://doi.org/10.1016/j.landurbplan.2010.02.007

Bossard, M., Heymann, Y., Lenco, M., Steenmans, C., 2006. CORINE Land Cover. Copenhagen, Denmark.

Bourdais, J.L., 1999. Utilisation d'indicateurs pour évaluer l'impact sur l'environnement de l'agriculture - Application à l'agriculture biologique en Aquitaine. Ingénieries - E A T 315.

Byerly, H., Balmford, A., Ferraro, P.J., Hammond Wagner, C., Palchak, E., Polasky, S., Ricketts, T.H., Schwartz, A.J., Fisher, B., 2018. Nudging pro-environmental behavior: evidence and opportunities. Front. Ecol. Environ. 16, 159-168. https://doi.org/10.1002/fee.1777

Cannon, A.R., Chamberlain, D.E., Toms, M.P., Hatchwell, B.J., Gaston, K.J., 2005. Trends in the use of private gardens by wild birds in Great Britain 1995-2002. J. Appl. Ecol. 42, 659-671. https://doi.org/10.1111/j.1365-2664.2005.01050.x 
Chase, S.K., Levine, A., 2018. Citizen Science: Exploring the Potential of Natural Resource Monitoring Programs to Influence Environmental Attitudes and Behaviors. Conserv. Lett. 11, e12382. https://doi.org/10.1111/conl.12382

Clayton, S., 2007. Domesticated nature: motivations for gardening and perceptions of environmental impact. J. Environ. Psychol. 27, 215-224. https://doi.org/10.1016/J.JENVP.2007.06.001

Clayton, S., Colléony, A., Conversy, P., Maclouf, E., Martin, L., Torres, A.C., Truong, M.X., Prévot, A.C., 2017. Transformation of experience: toward a new relationship with nature. Conserv. Lett. 10, 645-651. https://doi.org/10.1111/conl.12337

Clayton, S., Litchfield, C., Geller, E.S., 2013. Psychological science, conservation, and environmental sustainability. Front. Ecol. Environ. 11, 377-382. https://doi.org/10.1890/120351

Cooper, C.B., Dickinson, J., Phillips, T., Bonney. R., 2007. Citizen science as a tool for conservation in residential ecosystems. Ecol. Soc. 12.

Coppin, D.M., Eisenhauer, B.W., Krannich, R.S., 2002. Is Pesticide Use Socially Acceptable? A Comparison between Urban and Rural Settings. Soc. Sci. Q. 83, 379-394. https://doi.org/10.1111/1540-6237.00090

Cosquer, A., Raymond, R., Prévot-Julliard, A.C., 2012. Observations of everyday biodiversity: A new perspective for conservation? Ecol. Soc. 17. https://doi.org/10.5751/ES-04955-170402

Couvet, D., Jiguet, F., Julliard, R., Levrel, H., Teyssedre, A., 2008. Enhancing citizen contributions to biodiversity science and public policy. Interdiscip. Sci. Rev. 33, 95-103. https://doi.org/10.1179/030801808X260031

Crall, A.W., Jordan, R., Holfelder, K., Newman, G.J., Graham, J., Waller, D.M., 2013. The impacts of an invasive species citizen science training program on participant attitudes, 

behavior, and science literacy. Public Underst. Sci. 22, 745-764. https://doi.org/10.1177/0963662511434894

Daniels, G.D., Kirkpatrick, J.B., 2006. Does variation in garden characteristics influence the conservation of birds in suburbia? Biol. Conserv. 133, 326-335. https://doi.org/10.1016/j.biocon.2006.06.011

Deguines, N., de Flores, M., Loïs, G., Julliard, R., Fontaine, C., 2018. Fostering close encounters of the entomological kind. Front. Ecol. Environ. 16, 202-203. https://doi.org/10.1002/fee.1795

Deguines, N., Julliard, R., de Flores, M., Fontaine, C., 2016. Functional homogenization of flower visitor communities with urbanization. Ecol. Evol. 6, 1967-1976. https://doi.org/10.1002/ece3.2009

Diamond, J.M., 1989. Overview of recent extinctions, in: Western, D., Pearl, M.C. (Eds.), Conservation for the Twenty-First Century. Oxford University Press, pp. 37-41.

Dickinson, J.L., Zuckerberg, B., Bonter, D.N., 2010. Citizen science as an ecological research tool: challenges and benefits. Annu. Rev. Ecol. Evol. Syst. 41, 149-172. https://doi.org/10.1146/annurev-ecolsys-102209-144636

EEA, 2010. The European environment - state and outlook 2010: Synthesis (EEA Report No. No 1/2010). Copenhagen, Denmark.

European Commission, 2013. Flash Eurobarometer 379 Attitudes towards biodiversity.

Fontaine, B., Bergerot, B., Le Viol, I., Julliard, R., 2016. Impact of urbanization and gardening practices on common butterfly communities in France. Ecol. Evol. 6, 81748180. https://doi.org/10.1002/ece3.2526

Forister, M.L., Cousens, B., Harrison, J.G., Anderson, K., Thorne, J.H., Waetjen, D., Nice, C.C., De Parsia, M., Hladik, M.L., Meese, R., van Vliet, H., Shapiro, A.M., 2016. Increasing neonicotinoid use and the declining butterfly fauna of lowland California. 
524

Freeman, C., Dickinson, K.J.M., Porter, S., van Heezik, Y., 2012. "My garden is an expression of me": exploring householders' relationships with their gardens. J. Environ. Psychol. 32, 135-143. https://doi.org/10.1016/J.JENVP.2012.01.005

Gilburn, A.S., Bunnefeld, N., Wilson, J.M., Botham, M.S., Brereton, T.M., Fox, R., Goulson, D., 2015. Are neonicotinoid insecticides driving declines of widespread butterflies? PeerJ 3, e1402. https://doi.org/10.7717/peerj.1402

Goddard, M.A., Dougill, A.J., Benton, T.G., 2013. Why garden for wildlife? Social and ecological drivers, motivations and barriers for biodiversity management in residential landscapes. Ecol. Econ. 86, 258-273. https://doi.org/10.1016/j.ecolecon.2012.07.016

Goddard, M.A., Dougill, A.J., Benton, T.G., 2010. Scaling up from gardens: biodiversity conservation in urban environments. Trends Ecol. Evol. 25, 90-98. https://doi.org/10.1016/j.tree.2009.07.016

Godet, L., Devictor, V., 2018. What conservation does. Trends Ecol. Evol. 33, 720-730. https://doi.org/10.1016/J.TREE.2018.07.004

Hall, D.M., Camilo, G.R., Tonietto, R.K., Ollerton, J., Ahrné, K., Arduser, M., Ascher, J.S., Baldock, K.C.R., Fowler, R., Frankie, G., Goulson, D., Gunnarsson, B., Hanley, M.E., Jackson, J.I., Langellotto, G., Lowenstein, D., Minor, E.S., Philpott, S.M., Potts, S.G., Sirohi, M.H., Spevak, E.M., Stone, G.N., Threlfall, C.G., 2017. The city as a refuge for insect pollinators. Conserv. Biol. 31, 24-29. https://doi.org/10.1111/cobi.12840

Hines, J.M., Hungerford, H.R., Tomera, A.N., 1987. Analysis and Synthesis of Research on Responsible Environmental Behavior: A Meta-Analysis. J. Environ. Educ. 18, 1-8. https://doi.org/10.1080/00958964.1987.9943482

IPBES, 2019. Global assessment report on biodiversity and ecosystem services of the Intergovernmental Science- Policy Platform on Biodiversity and Ecosystem Services. 
IPBES Secretariat, Bonn, Germany.

549 Jordan, R.C., Gray, S.A., Howe, D. V., Brooks, W.R., Ehrenfeld, J.G., 2011. Knowledge gain and behavioral change in citizen-science programs. Conserv. Biol. 25, 1148-1154. https://doi.org/10.1111/j.1523-1739.2011.01745.x

La Sorte, F.A., McKinney, M.L., Pyšek, P., 2007. Compositional similarity among urban floras within and across continents: biogeographical consequences of human-mediated biotic interchange. Glob. Chang. Biol. 13, 913-921. https://doi.org/10.1111/j.1365-

Levé, M., Baudry, E., Bessa-Gomes, C., 2018. Domestic gardens as favorable pollinator habitats in impervious landscapes. Sci. Total Environ. 647, 420-430. https://doi.org/10.1016/j.scitotenv.2018.07.310

Lewandowski, E.J., Oberhauser, K.S., 2017. Butterfly citizen scientists in the United States increase their engagement in conservation. Biol. Conserv. 208, 106-112. https://doi.org/10.1016/J.BIOCON.2015.07.029

Lorrillière, R., Bessa-gomes, C., Deguines, N., Fontaine, B., Jiguet, F., Poitevin, M., Turpin, S., Chiron, F., 2018. Winter bird survey in French gardens, two complementary schemes for a wide array of questions. Bird census news 31, 10-17.

Luppi, M., Dondina, O., Orioli, V., Bani, L., 2018. Local and landscape drivers of butterfly richness and abundance in a human-dominated area. Agric. Ecosyst. Environ. 254, 138148. https://doi.org/10.1016/J.AGEE.2017.11.020

Manly, B.F.J., 2006. Randomization, bootstrap and Monte Carlo methods in biology, 3rd ed. Chapman \& Hall/ CRC.

Marzluff, J.M., 2001. Worldwide urbanization and its effects on birds, in: Avian Ecology and Conservation in an Urbanizing World. Springer US, Boston, MA, pp. 19-47. https://doi.org/10.1007/978-1-4615-1531-9_2 
573 McKinley, D.C., Miller-Rushing, A.J., Ballard, H.L., Bonney, R., Brown, H., Cook-Patton, 574 S.C., Evans, D.M., French, R.A., Parrish, J.K., Phillips, T.B., Ryan, S.F., Shanley, L.A., 575 Shirk, J.L., Stepenuck, K.F., Weltzin, J.F., Wiggins, A., Boyle, O.D., Briggs, R.D., 576 Chapin, S.F., Hewitt, D.A., Preuss, P.W., Soukup, M.A., 2017. Citizen science can 577 improve conservation science, natural resource management, and environmental 578 protection. Biol. Conserv. 208, 15-28. https://doi.org/10.1016/j.biocon.2016.05.015

579 McKinney, M.L., 2006. Urbanization as a major cause of biotic homogenization. Biol.

580 Conserv. 127, 247-260. https://doi.org/10.1016/j.biocon.2005.09.005

581 Mimet, A., Kerbiriou, C., Simon, L., Julien, J.-F., Raymond, R., 2020. Contribution of private gardens to habitat availability, connectivity and conservation of the common pipistrelle in Paris. Landsc. Urban Plan. 193, 103671. https://doi.org/10.1016/J.LANDURBPLAN.2019.103671

Osbaldiston, R., Schott, J.P., 2012. Environmental sustainability and behavioral science. Environ. Behav. 44, 257-299. https://doi.org/10.1177/0013916511402673

Pardee, G.L., Philpott, S.M., 2014. Native plants are the bee's knees: local and landscape predictors of bee richness and abundance in backyard gardens. Urban Ecosyst. 17, 641-

Ponciano, L., Brasileiro, F., 2014. Finding volunteers' engagement profiles in human computation for citizen science projects. Hum. Comput. 1, 245-264. https://doi.org/10.15346/hc.v1i2.12

Prévot, A.-C., Cheval, H., Raymond, R., Cosquer, A., 2018. Routine experiences of nature in cities can increase personal commitment toward biodiversity conservation. Biol. de biodiversité, des opportunités d'apprentissage, in: Las Vergnas, O. (Ed.), Le E- 

Learning Informel? Des Apprentissages Diffus, Noyés Dans La Participation En Ligne. Editions des archives contemporaines, pp. 59-73. https://doi.org/10.17184/eac.780

Princé, K., Zuckerberg, B., 2015. Climate change in our backyards: the reshuffling of North America's winter bird communities. Glob. Chang. Biol. 21, 572-585. https://doi.org/10.1111/gcb.12740

R Core Team, 2018. R: a language and environment for statistical computing.

Riboulot-Chetrit, M., Simon, L., Raymond, R., 2018. Making space for disorder in the garden: developing biophilia to conciliate aesthetics and biodiversity, in: Glatron, S., Granchamp, L. (Eds.), The Urban Garden City. Shaping the City with Gardens through History. Springer, pp. 165-184. https://doi.org/10.1007/978-3-319-72733-2_9

Rudd, H., Vala, J., Schaefer, V., 2002. Importance of backyard habitat in a comprehensive biodiversity conservation strategy: a connectivity analysis of urban green spaces. Restor. Ecol. 10, 368-375. https://doi.org/10.1046/j.1526-100X.2002.02041.x

Schultz, P.W., 2014. Strategies for promoting proenvironmental behavior. Eur. Psychol. 19, 107-117. https://doi.org/10.1027/1016-9040/a000163

Schultz, P.W., 2011. Conservation means behavior. Conserv. Biol. 25, 1080-1083. https://doi.org/10.1111/j.1523-1739.2011.01766.x

Sharma, N., Greaves, S., Siddharthan, A., Anderson, H., Robinson, A., Colucci-Gray, L., Wibowo, A.T., Bostock, H., Salisbury, A., Roberts, S., Slawson, D., van der Wal, R., 2019. From citizen science to citizen action: analysing the potential for a digital platform to cultivate attachments to nature. J. Sci. Commun. 18, A07. https://doi.org/10.22323/2.18010207

Silvertown, J., Harvey, M., Greenwood, R., Dodd, M., Rosewell, J., Rebelo, T., Ansine, J., McConway, K., 2015. Crowdsourcing the identification of organisms: A case-study of iSpot. Zookeys 480, 125-146. https://doi.org/10.3897/zookeys.480.8803 
623

624

625

626

627

628

629

630

631

632

633

634

635

636

637

638

639

640

641

642

643

Sperling, C.D., Lortie, C.J., 2010. The importance of urban backgardens on plant and invertebrate recruitment: a field microcosm experiment. Urban Ecosyst. 13, 223-235. https://doi.org/10.1007/s11252-009-0114-y

Stern, P.C., 2000. Toward a coherent theory of environmentally significant behavior. J. Soc. Issues 56, 407-424. https://doi.org/10.1111/0022-4537.00175

Toomey, A.H., Domroese, M.C., 2013. Can citizen science lead to positive conservation attitudes and behaviors? Hum. Ecol. Rev. 20, 50-62. https://doi.org/10.2307/24707571

Toomey, A.H., Knight, A.T., Barlow, J., 2017. Navigating the space between research and implementation in conservation. Conserv. Lett. 10, 619-625. https://doi.org/10.1111/conl.12315

Torres, A.C., Nadot, S., Prévot, A.-C., 2017. Specificities of French community gardens as environmental stewardships. Ecol. Soc. 22, art28. https://doi.org/10.5751/ES-09442220328

Uren, H. V, Dzidic, P.L., Bishop, B.J., 2015. Exploring social and cultural norms to promote ecologically sensitive residential garden design. Landsc. Urban Plan. 137, 76-84. https://doi.org/10.1016/J.LANDURBPLAN.2014.12.008

Zuur, A.F., Ieno, E.N., Walker, N., Saveliev, A.A., Smith, G.M., 2009. Mixed effects models and extensions in ecology with R, Statistics for Biology and Health. Springer-Verlag, New York, NY. https://doi.org/10.1007/978-0-387-87458-6 
Table 1: Results from final mixed-effects models. Predictors' estimates are shown for the

645 linear mixed-effects model (Nectar resources) and the generalized linear mixed-effects model

646 (Pesticide use), along with their associated 95\% confidence intervals, and $P$-values. Sust.

647 participation, Urban. cont., Pres. veg. garden, and Pres. fruit trees stand for sustained

648 participation, urbanization context, presence of a vegetable garden within the backyard (vs

649 absence), and presence of fruit trees within the backyard (vs absence) respectively. Two-way

650 interactions associated to a $P$-value $>0.05$ were sequentially removed from the complete

651 models (see 2.3).

\begin{tabular}{llcccc}
\multirow{2}{*}{ Response variable } & Estimate & $\begin{array}{c}\text { Lower } \\
\text { CI }\end{array}$ & $\begin{array}{c}\text { Upper } \\
\text { CI }\end{array}$ & $\boldsymbol{p}$ \\
\hline Nectar resources & Sust. participation & 0.200 & 0.125 & 0.275 & $<0.001$ \\
& Within-year participation & 0.117 & 0.043 & 0.190 & 0.002 \\
& Backyard size & 1.235 & 1.085 & 1.385 & $<0.001$ \\
& Urban. cont. & -0.012 & -0.018 & -0.006 & $<0.001$ \\
& Pres. veg. garden & 0.566 & 0.379 & 0.753 & $<0.001$ \\
& Pres. fruit trees & 0.783 & 0.572 & 0.994 & $<0.001$ \\
& Longitude & 0.049 & -0.004 & 0.101 & 0.068 \\
& Latitude & 0.083 & 0.012 & 0.153 & 0.022 \\
& Sust. participation x Backyard size & - & - & - & - \\
& Sust. participation x Urban. cont. & - & - & - & - \\
& Sust. participation x Pres. veg. garden & - & - & - & - \\
& Sust. participation x Pres. fruit trees & - & - & - & - \\
& & & & & \\
& Sust. participation & -0.501 & -0.659 & -0.343 & $<0.001$ \\
& Within-year participation & 0.075 & -0.028 & 0.178 & 0.156 \\
& Backyard size & 0.229 & 0.022 & 0.436 & 0.030 \\
& Urban. cont. & 0.007 & -0.002 & 0.015 & 0.127 \\
& Pres. veg. garden & -0.285 & -0.809 & 0.240 & 0.288 \\
Pres. fruit trees & 0.028 & -0.597 & 0.653 & 0.930 \\
& Longitude & 0.077 & 0.007 & 0.148 & 0.032 \\
& Latitude & -0.046 & -0.142 & 0.049 & 0.342 \\
& Type of pesticide use information & 3.793 & 3.470 & 4.116 & $<0.001$ \\
Sust. participation x Backyard size & - & - & - & - \\
& Sust. participation x Urban. cont. & - & - & - & - \\
& Sust. participation x Pres. veg. garden & 0.270 & 0.135 & 0.406 & $<0.001$ \\
& Sust. participation x Pres. fruit trees & 0.160 & 0.002 & 0.317 & 0.047 \\
\hline & & & & &
\end{tabular}


(a)

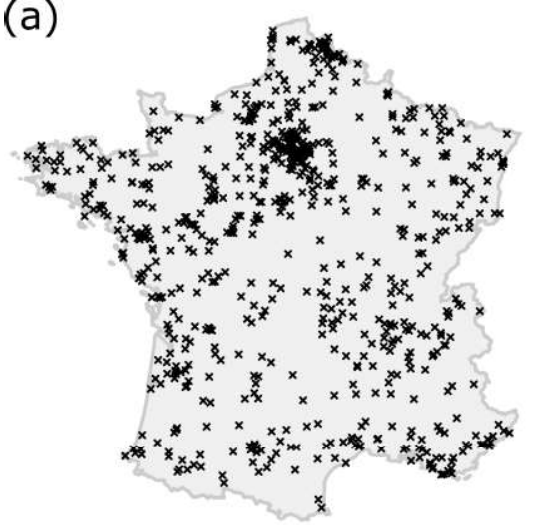

(d)

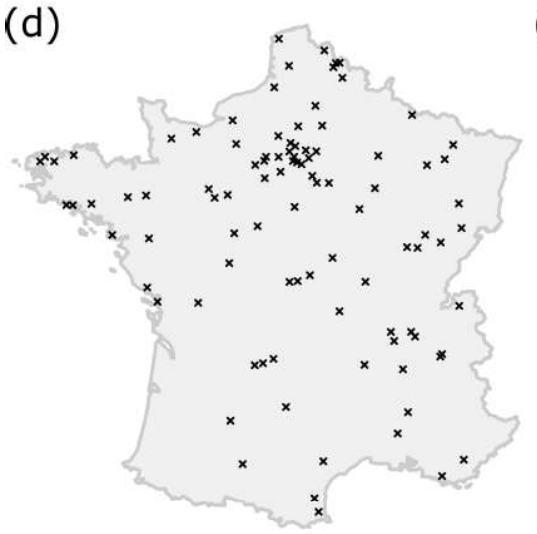

(g)

(e)

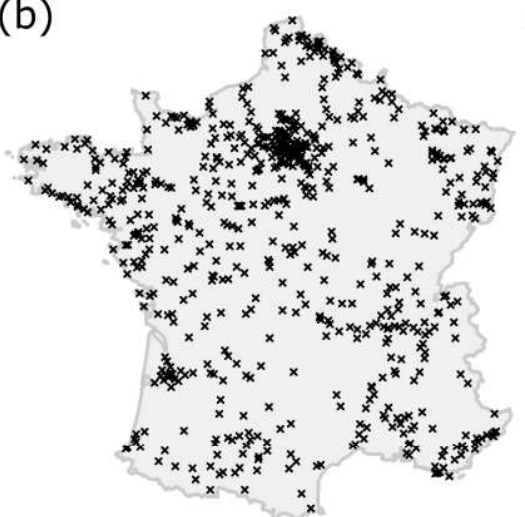

(c)

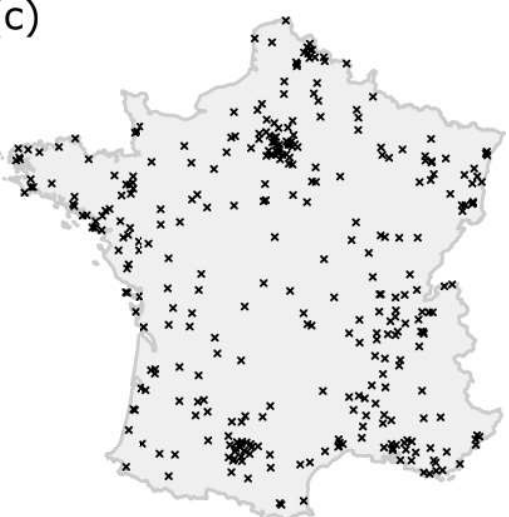

(f)
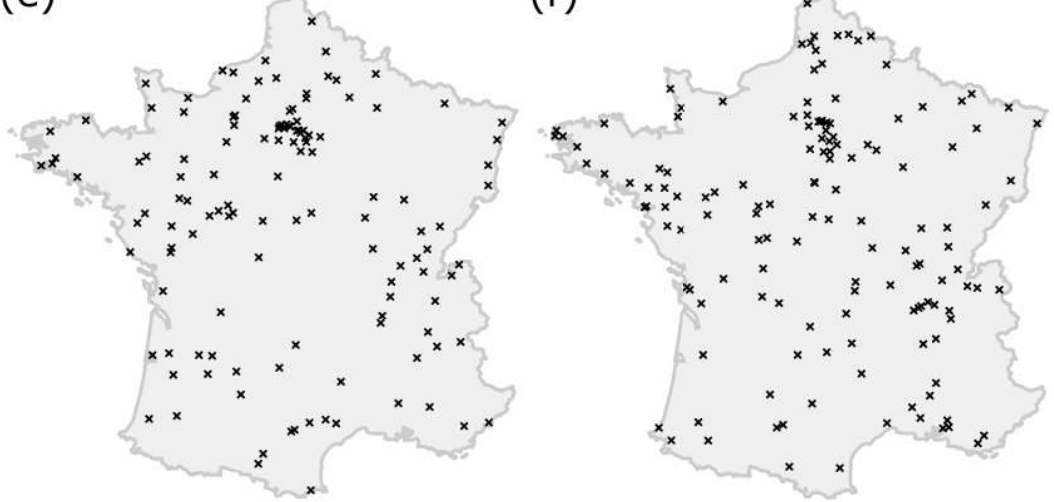
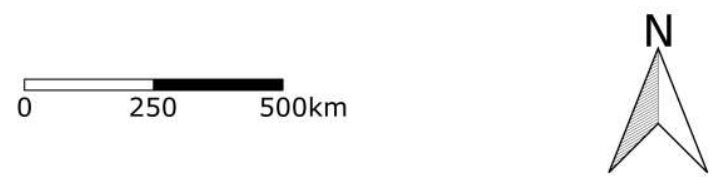

656

Figure 1. Localization of the 2362 backyards. From (a) to (g), volunteers joining the

657 Butterfly citizen science project in $2006(\mathrm{n}=767), 2007(\mathrm{n}=722), 2008(\mathrm{n}=355), 2009(\mathrm{n}=$ 97), $2010(\mathrm{n}=130), 2011(\mathrm{n}=144)$, and $2012(\mathrm{n}=147)$ respectively. 


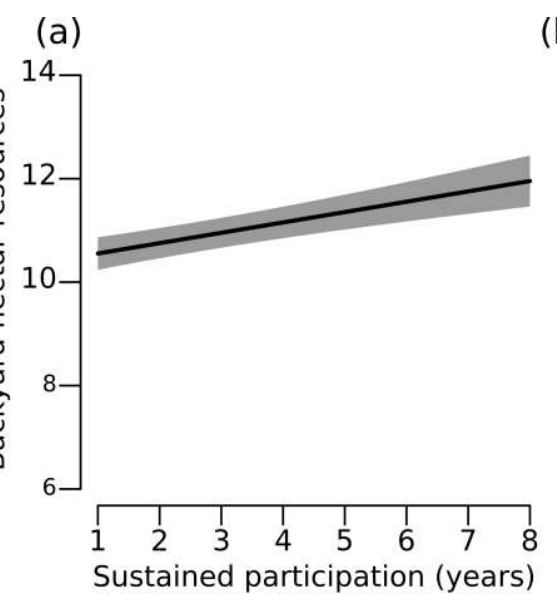

(d)

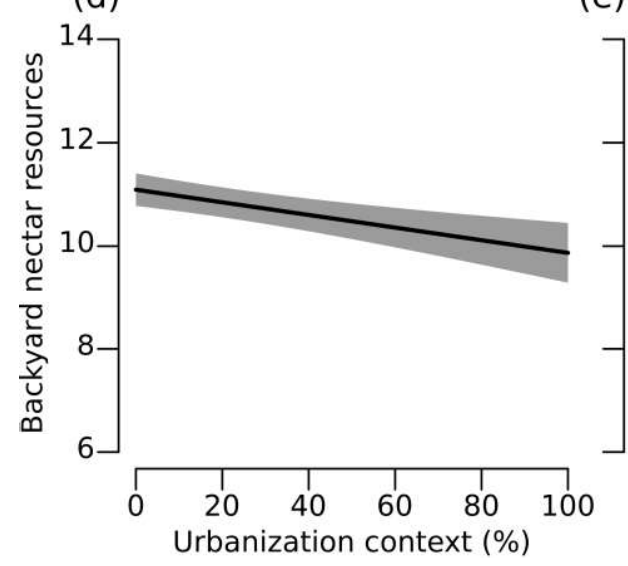

(b)

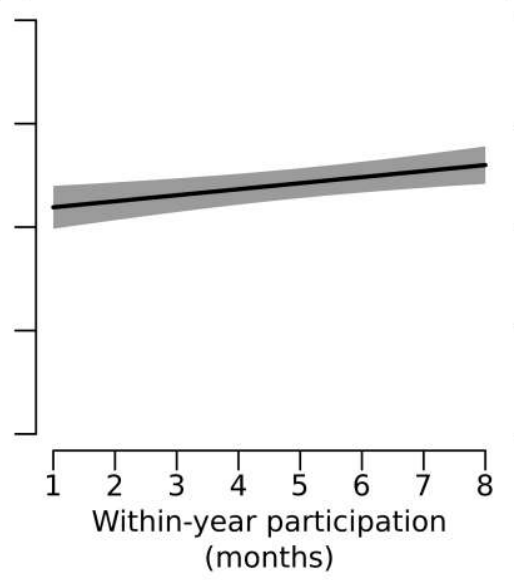

(e)

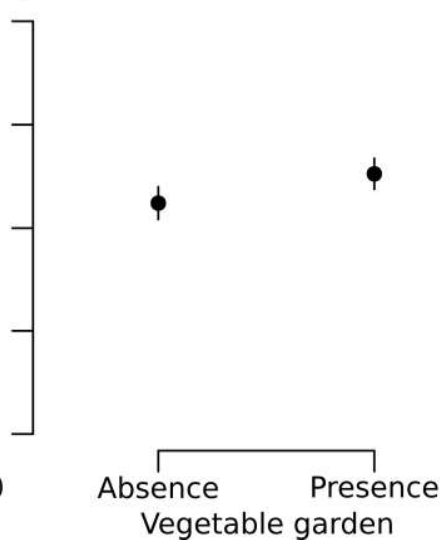

(c)

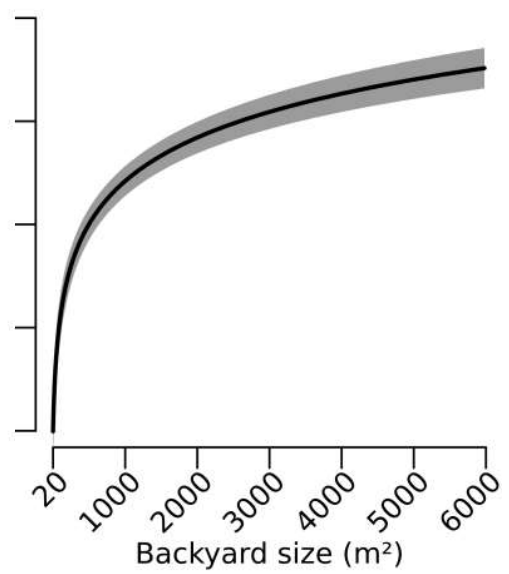

(f)

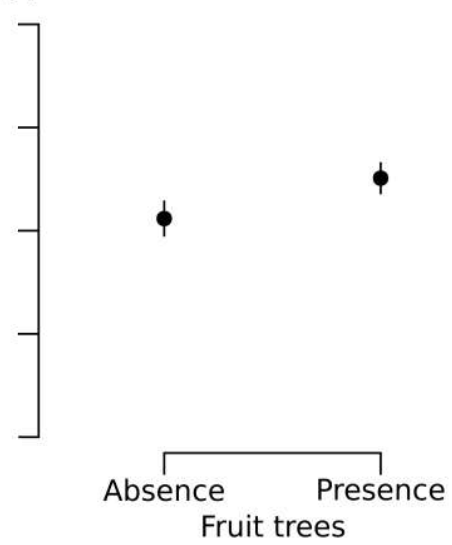

661 Figure 2. Predictors of backyard nectar resources. Effect of (a) sustained participation, (b)

662 within-year participation, (c) backyard size (back-transformed in $\mathrm{m}^{2}$ ), (d) backyard

663 urbanization context (percentage of urban areas in backyard's municipality), (e) presence of a

664 vegetable garden within the backyard, and (f) presence of fruit trees within the backyard. In

665 (a-d), lines are predictions from the linear mixed-effects model and grey bands are associated

$66695 \%$ confidence intervals. In (e) and (f), bars represent 95\% confidence intervals. 
(a)

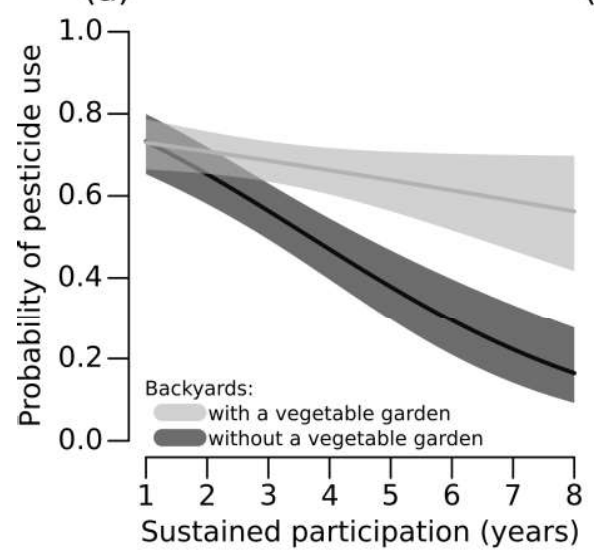

(b)

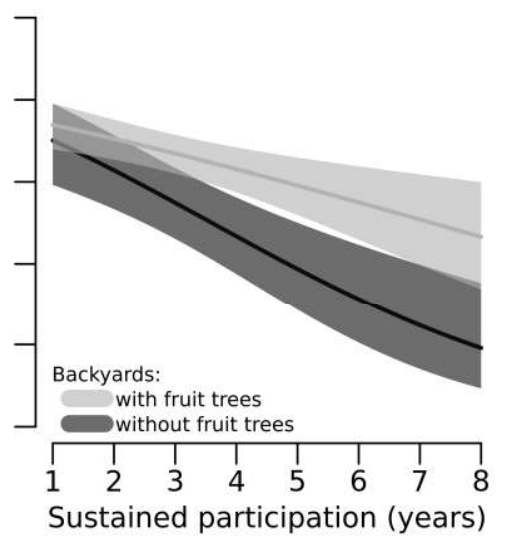

(c)

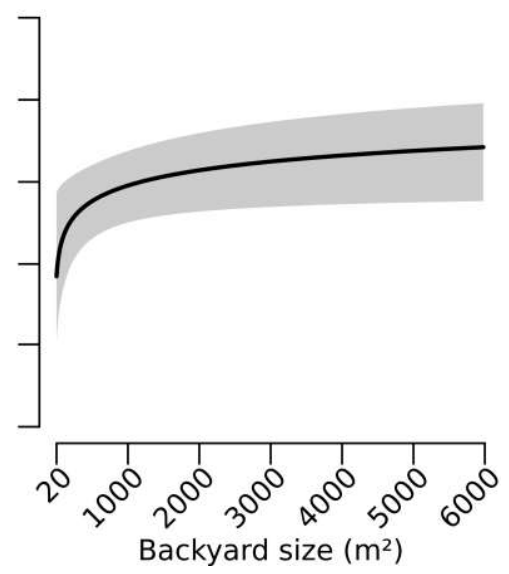

669 Figure 3. Predictors of pesticide use in backyards. Effect of (a) the interaction between

670 sustained participation and presence of a vegetable garden within the backyard, (b) the

671 interaction between sustained participation and presence of fruit trees within the backyard,

672 and (c) backyard size (back-transformed in $\mathrm{m}^{2}$ ). Lines are predictions from the generalized

673 mixed-effects model, and grey bands are associated $95 \%$ confidence intervals. 
1 Table 1: Results from final mixed-effects models. Predictors' estimates are shown for the

2 linear mixed-effects model (Nectar resources) and the generalized linear mixed-effects model

3 (Pesticide use), along with their associated 95\% confidence intervals, and $P$-values. Sust.

4 participation, Urban. cont., Pres. veg. garden, and Pres. fruit trees stand for sustained

5 participation, urbanization context, presence of a vegetable garden within the backyard (vs

6 absence), and presence of fruit trees within the backyard (vs absence) respectively. Two-way

7 interactions associated to a $P$-value $>0.05$ were sequentially removed from the complete

8 models (see 2.3).

\begin{tabular}{llcccc}
\multirow{2}{*}{ Response variable } & Estimate & $\begin{array}{c}\text { Lower } \\
\text { CI }\end{array}$ & $\begin{array}{c}\text { Upper } \\
\text { CI }\end{array}$ & $\boldsymbol{p}$ \\
\hline Nectar resources & Sust. participation & 0.200 & 0.125 & 0.275 & $<0.001$ \\
& Within-year participation & 0.117 & 0.043 & 0.190 & 0.002 \\
& Backyard size & 1.235 & 1.085 & 1.385 & $<0.001$ \\
& Urban. cont. & -0.012 & -0.018 & -0.006 & $<0.001$ \\
& Pres. veg. garden & 0.566 & 0.379 & 0.753 & $<0.001$ \\
& Pres. fruit trees & 0.783 & 0.572 & 0.994 & $<0.001$ \\
& Longitude & 0.049 & -0.004 & 0.101 & 0.068 \\
& Latitude & 0.083 & 0.012 & 0.153 & 0.022 \\
& Sust. participation x Backyard size & - & - & - & - \\
& Sust. participation x Urban. cont. & - & - & - & - \\
& Sust. participation x Pres. veg. garden & - & - & - & - \\
& Sust. participation x Pres. fruit trees & - & - & - & - \\
& & & & & \\
& Sust. participation & -0.501 & -0.659 & -0.343 & $<0.001$ \\
& Within-year participation & 0.075 & -0.028 & 0.178 & 0.156 \\
& Backyard size & 0.229 & 0.022 & 0.436 & 0.030 \\
& Urban. cont. & 0.007 & -0.002 & 0.015 & 0.127 \\
& Pres. veg. garden & -0.285 & -0.809 & 0.240 & 0.288 \\
Pres. fruit trees & 0.028 & -0.597 & 0.653 & 0.930 \\
& Longitude & 0.077 & 0.007 & 0.148 & 0.032 \\
& Latitude & -0.046 & -0.142 & 0.049 & 0.342 \\
Type of pesticide use information & 3.793 & 3.470 & 4.116 & $<0.001$ \\
& Sust. participation x Backyard size & - & - & - & - \\
& Sust. participation x Urban. cont. & - & - & - & - \\
& Sust. participation x Pres. veg. garden & 0.270 & 0.135 & 0.406 & $<0.001$ \\
& Sust. participation x Pres. fruit trees & 0.160 & 0.002 & 0.317 & 0.047 \\
\hline & & & & &
\end{tabular}


(a)

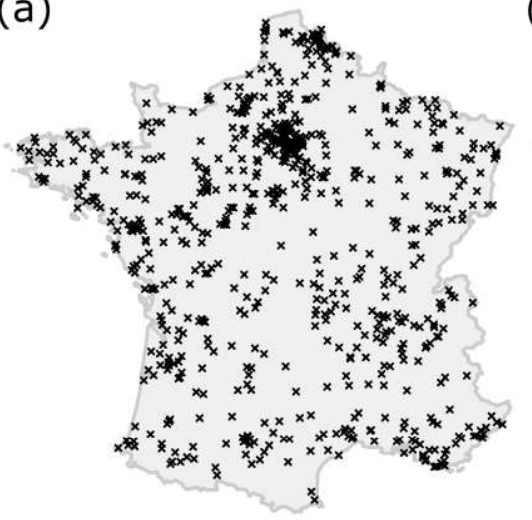

(d)

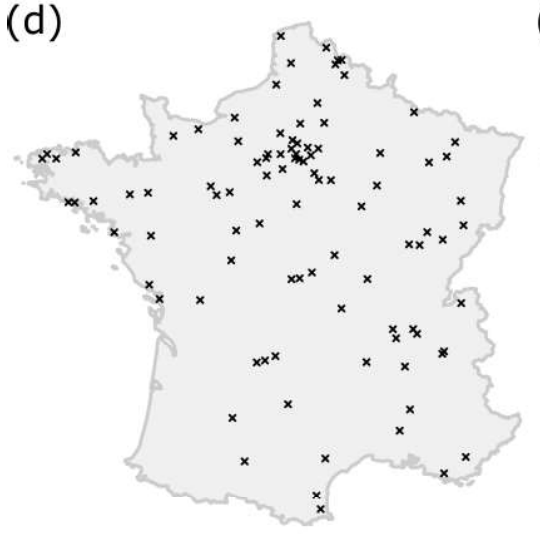

(g)

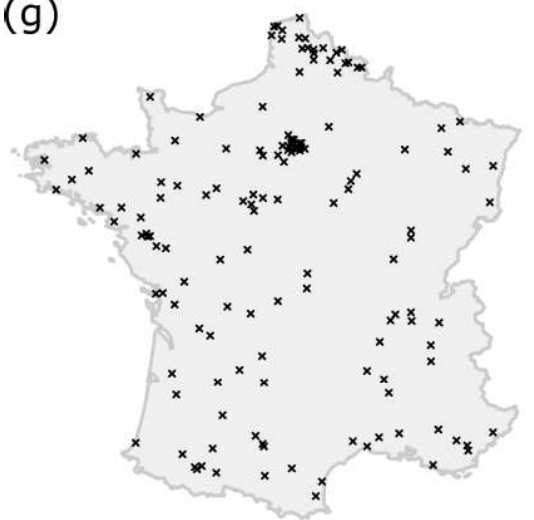

(b)

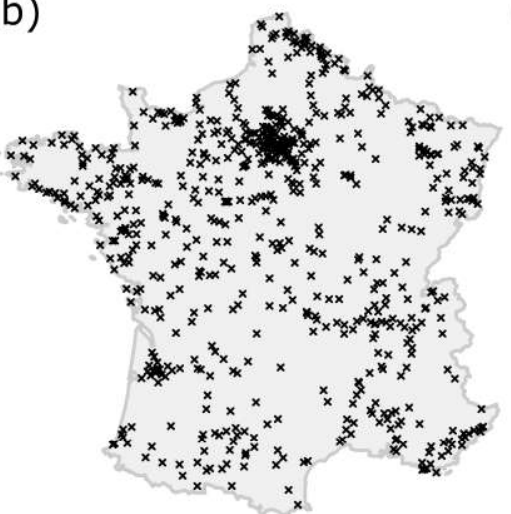

(e)

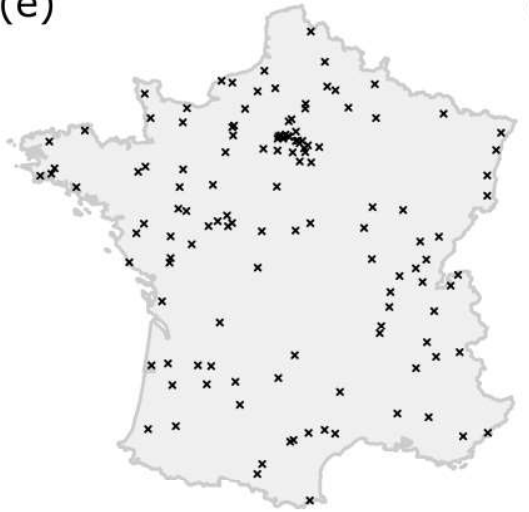

(c)

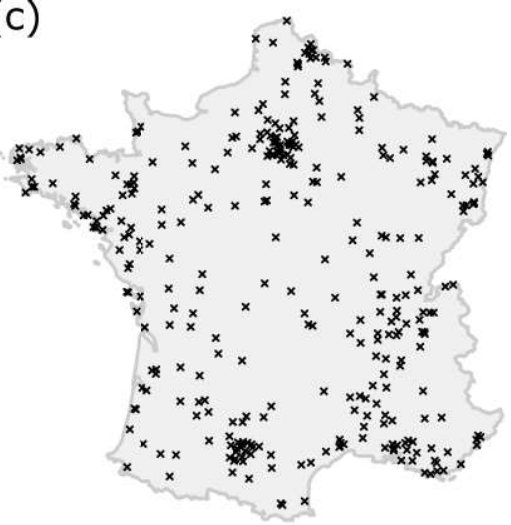

(f)

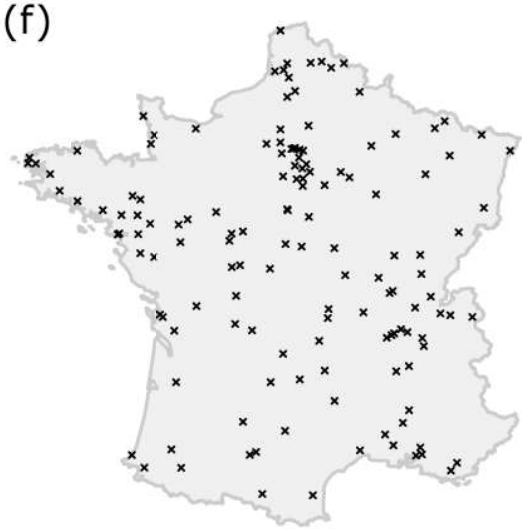

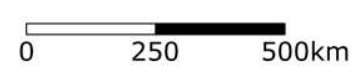

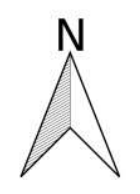


(a)

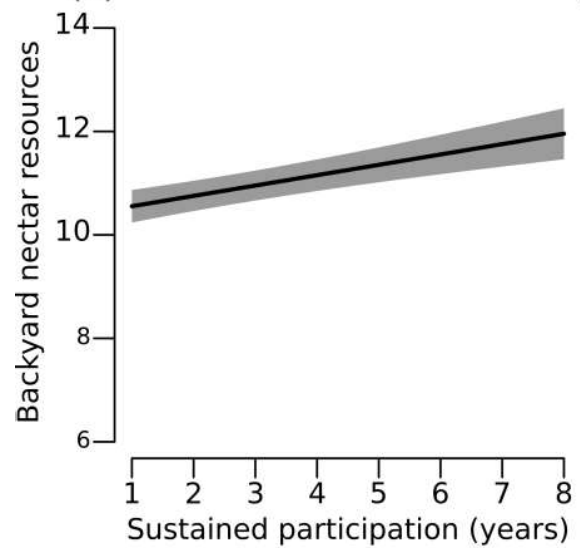

(d)

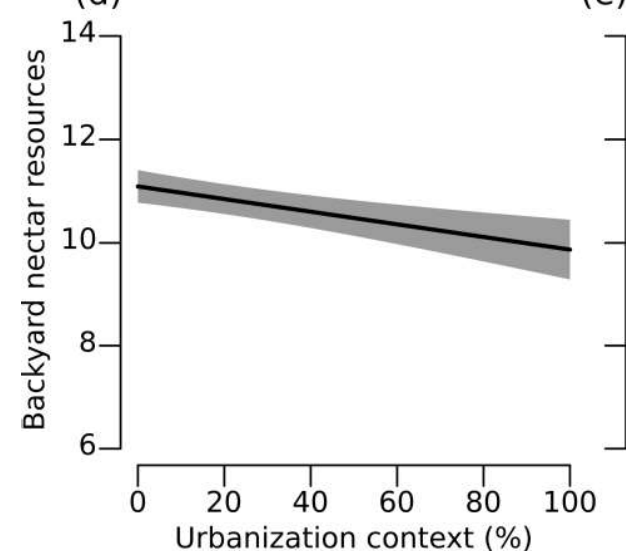

1 (b)

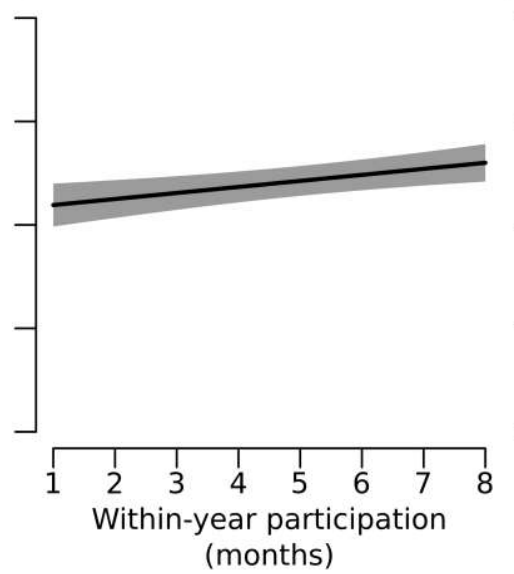

(e)

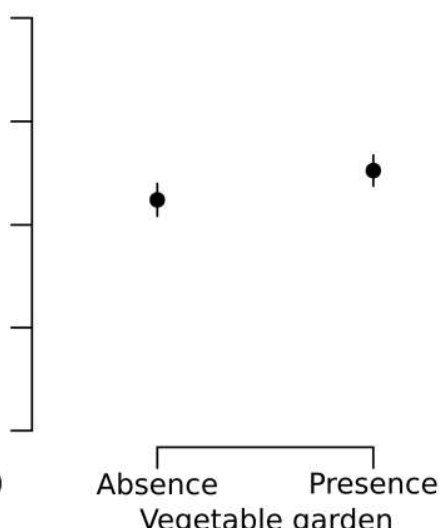

(c)

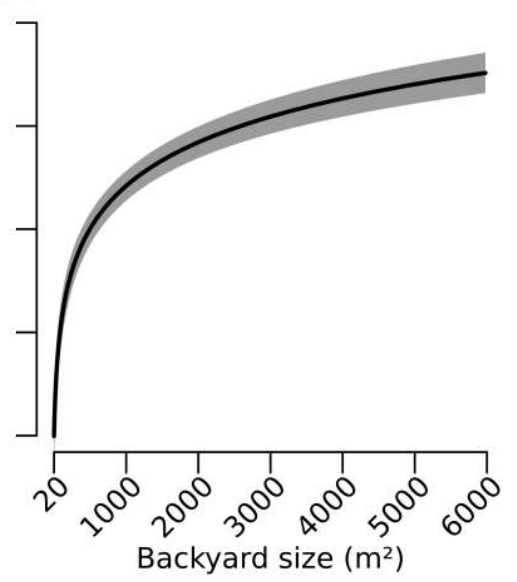

(f)

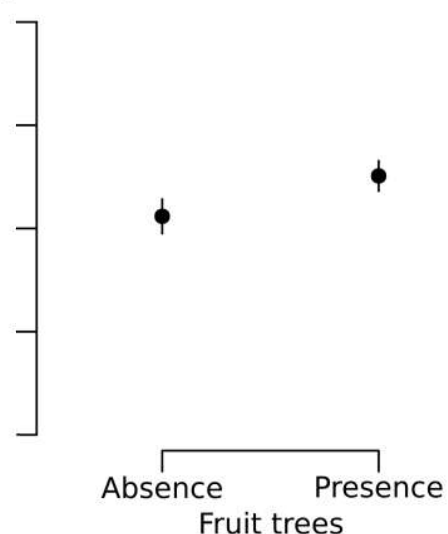


(a)

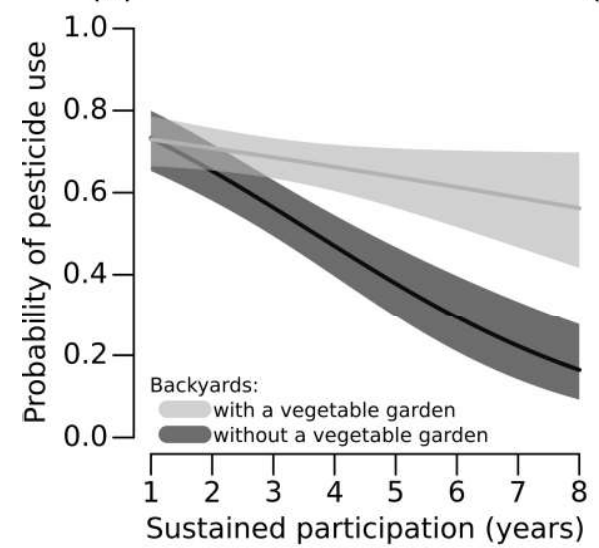

(b)

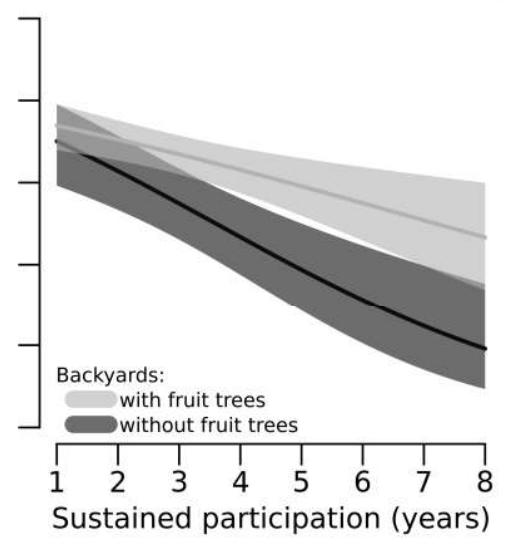

(c)

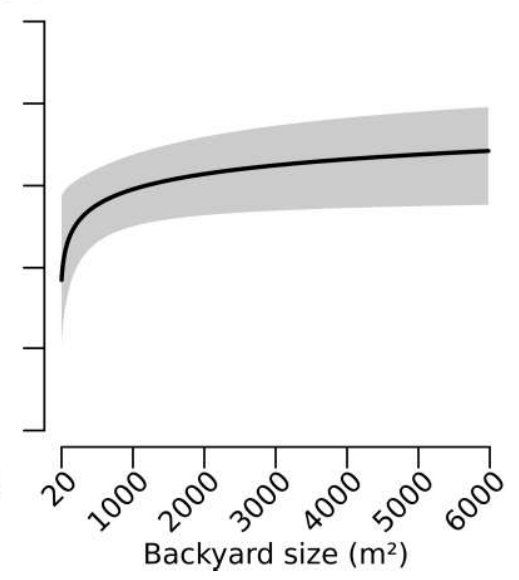

